\title{
ИССЛЕДОВАНИЕ ОГНЕСТОЙКИХ ШЕРСТЯНЫХ ВОЛОКОН МЕТОДОМ ИК-СПЕКТРОСКОПИИ
}

O. KIRRET, Lilja LAHE. TULEKINDLATE VILLKIUDUDE UURIMINE INFRAPUNASE SPEKTROSKOOPIA MEETODIL

O. KIRRET, Lilya LAHE. INVESTIGATION OF FLAMEPROOF WOOL FIBRES BY INFRARED SPECTROSCOPIC METHOD

Требования современных стандартов побуждают исследователей повышать огнестойкость натуральной шерсти прибавлением антипиренов (галоген-, фосфор-, бор-, серусодержащие соединения и др.) $\left[{ }^{1-3}\right]$.

Обработкой шерстяных волокон водными растворами фторкомплексов титана и циркония, а также хлорэндиковой кислотой достигнута высокая огнестойкость (кислородный индекс 28-32) при прочности материала к стирке [3,4].

Высокая огнестойкость в результате применения фтортитаната объясняется меньшим размером этого комплекса, по сравнению с комплексами ряда других тяжелых металлов, а также более глубокой диффузией агента в шерстяное волокно и прочным его связыванием со структурой шерсти $\left[{ }^{4,5}\right]$.

В последнее время ИК-спектроскопия занимает довольно скромное место при анализе натуральной шерсти, что связано с перекрыванием полос валентных колебаний NH амидной полосы в области спектра 3 мкм [6].

В настоящей же работе этот дешевый, общедоступный химикам метод используется для анализа модифицированной разными добавками шерсти в основном в области спектра 9 мкм, где амидные полосы не перекрываются.

ИК-спектры проб и их пиролизных остатков снимали на спектрофотометре «Specord 75 IR» фирмы «Zeiss» (ГДР), используя технику таблетирования с КВч. Пиролиз проводили в пиролизаторе газового хроматографа «Chrom 5» в потоке гелия при температурах 300 и $500^{\circ} \mathrm{C}$.

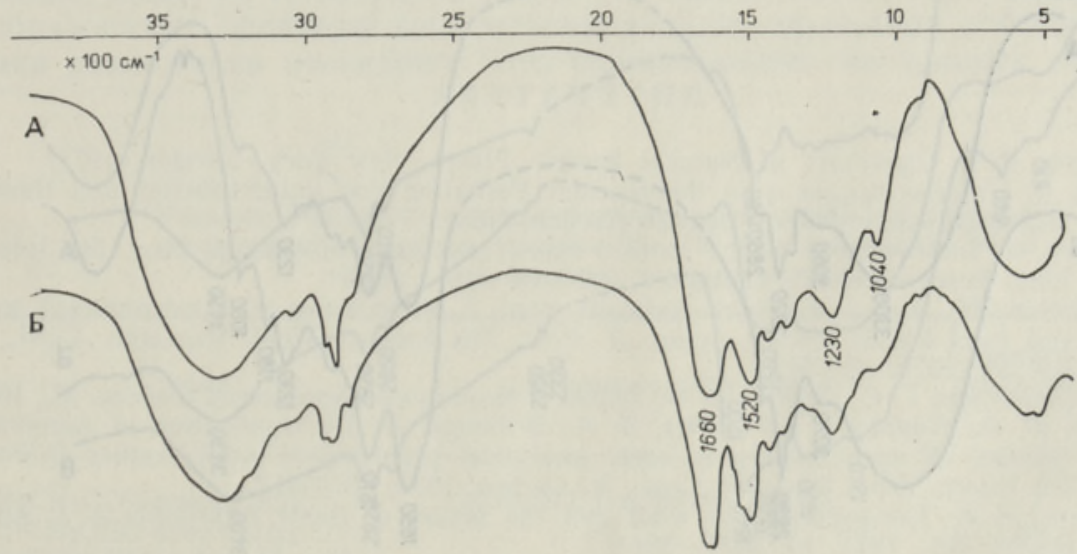

Рис. 1. ИК-спектры натуральной шерсти (А) и обработанной 10\%-ным раствором $\mathrm{K}_{2} \mathrm{TiF}_{6}$ (Б). 
Анализируемые пробы: 1) натуральная шерсть; 2) она же, обработанная $10 \%$-ным раствором $\mathrm{K}_{2} \mathrm{TiF}_{6} ; 3$ ) она же, обработанная $39,4 \%$-ной хлорэндиковой кислотой; 4) она же, обработанная смесью $10 \%$-ного раствора $\mathrm{K}_{2} \mathrm{TiF}_{6}$ и $10 \%$-ной хлорэндиковой кислотой.

Сравнивая спектры чистой шерсти и обработанной калийфтортитанатом, можно видеть, что механический переход полосы $600 \mathrm{~cm}^{-1}$ огнестойкого агента в спектр модифицированной пробы отсутствует - очевидно, действие агента на шерсть проходит по амидным группам и через $\mathrm{CH}_{2}$ - и $\mathrm{CH}_{3}$-структуры, так как вид этих полос несколько изменился по сравнению с наблюдаемым для исходной шерсти (рис. 1).

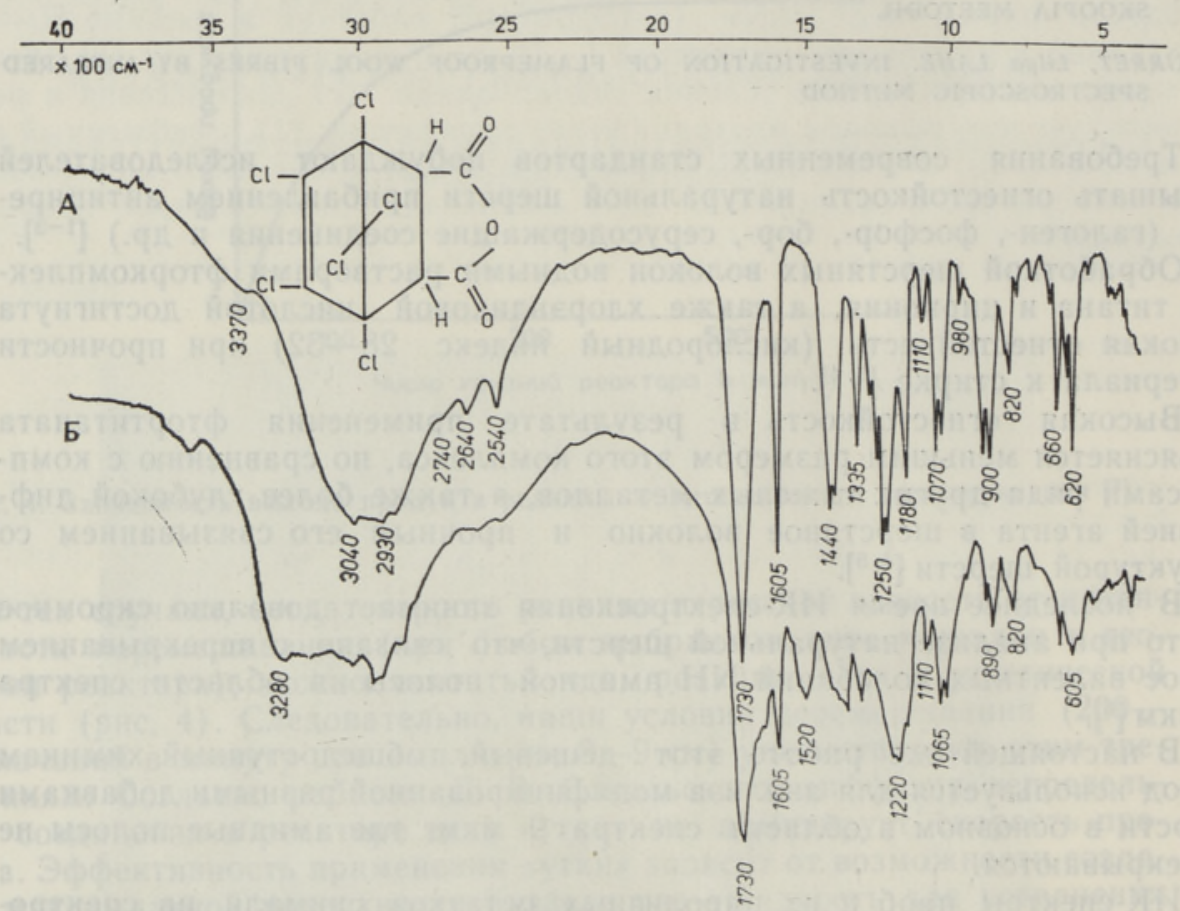

Рис. 2. ИК-спектры чистой хлорэндиковой кислоты (A) и шерсти, обработанной $39,4 \%$-ным раствором хлорэндиковой кислоты (Б).

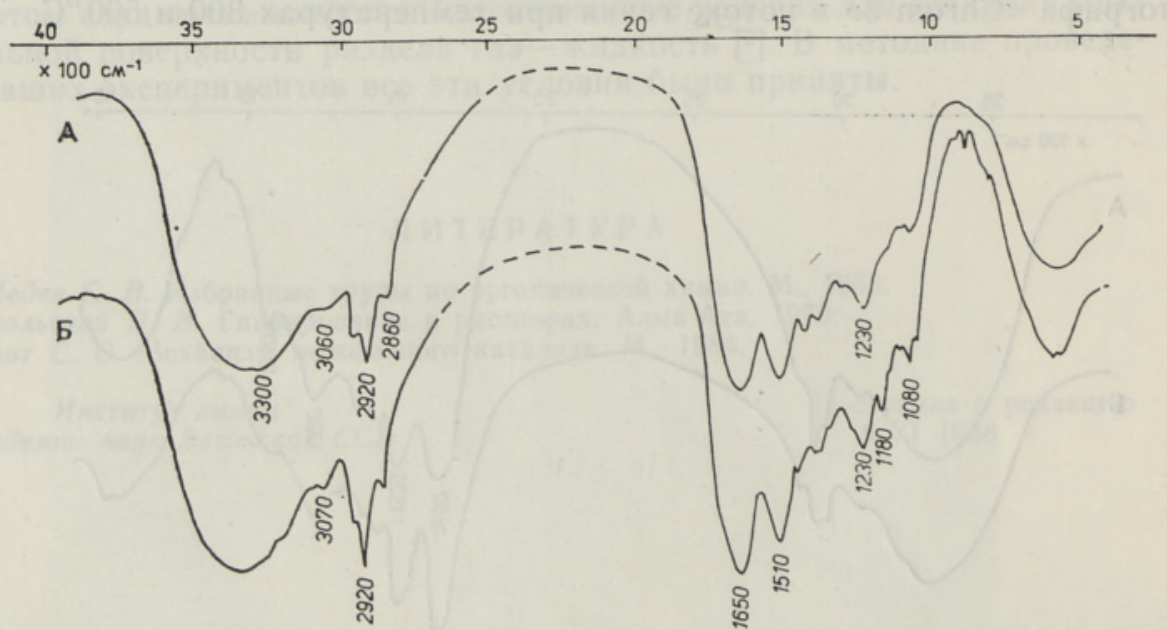

Рис. 3. ИК-спектры натуральной шерсти (А) и обработанной 10\%-ными растворами $\mathrm{K}_{2} \mathrm{TiF}_{6}$ и хлорэндиковой кислоты (Б). 
Чистая хлорэндиковая кислота характеризуется в ИК-области многими острыми интенсивными полосами, которые ясно выделяются и в спектре обработанной этим антипиреном шерсти (рис. 2 , А, Б).

Материал, полученный при модификации шерсти смесью обоих антипиренов с равным содержанием компонентов (проба № 4), характеризуется дополнительными полосами поглощения (область 9 мкм - полосы 1080 и $1180 \mathrm{~cm}^{-1}$ ) к спектру исходной шерсти (рис. 3).

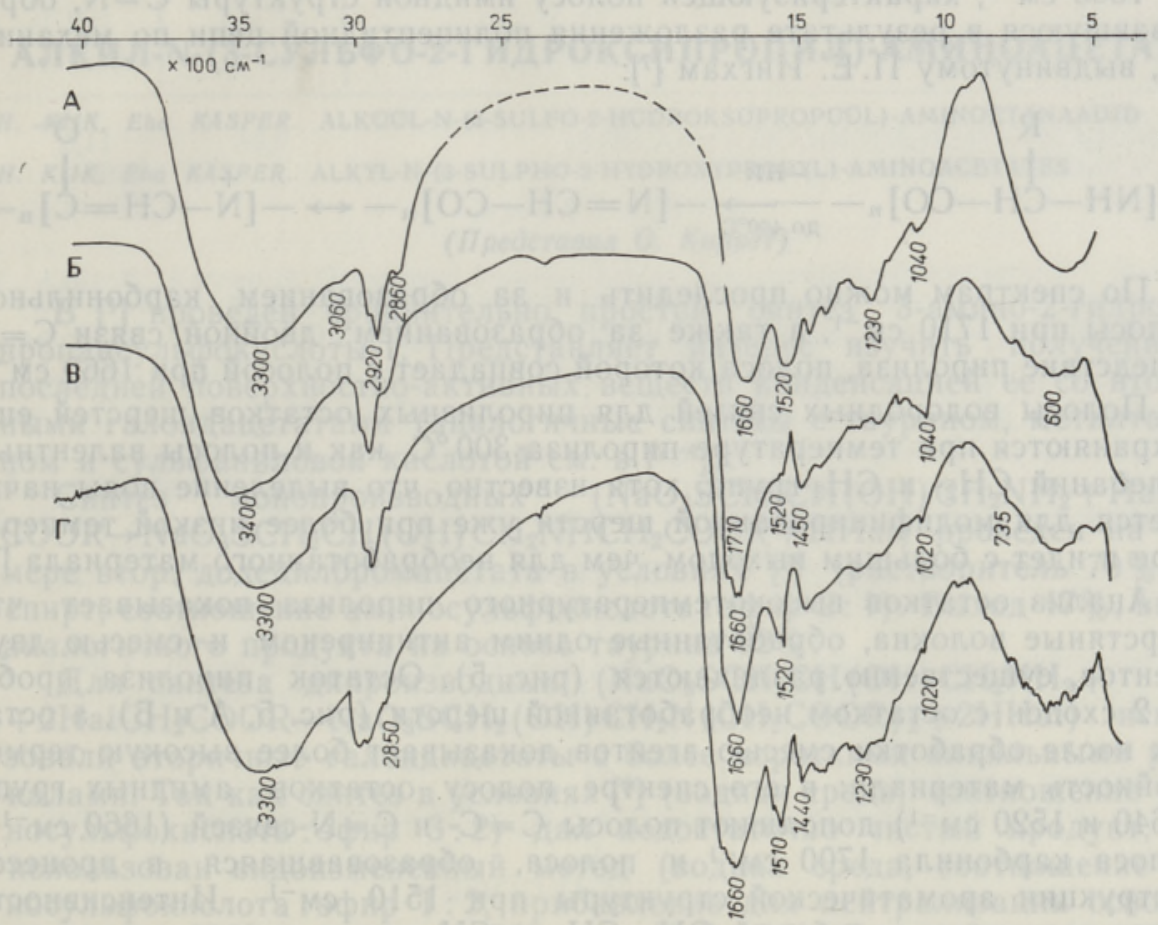

Рис. 4. ИК-спектры натуральной шерсти (А) и пиролизных остатков натуральной шерсти (Б), проб № 2 (В) и № 4 (Г). Температура пиролиза $300^{\circ} \mathrm{C}$.

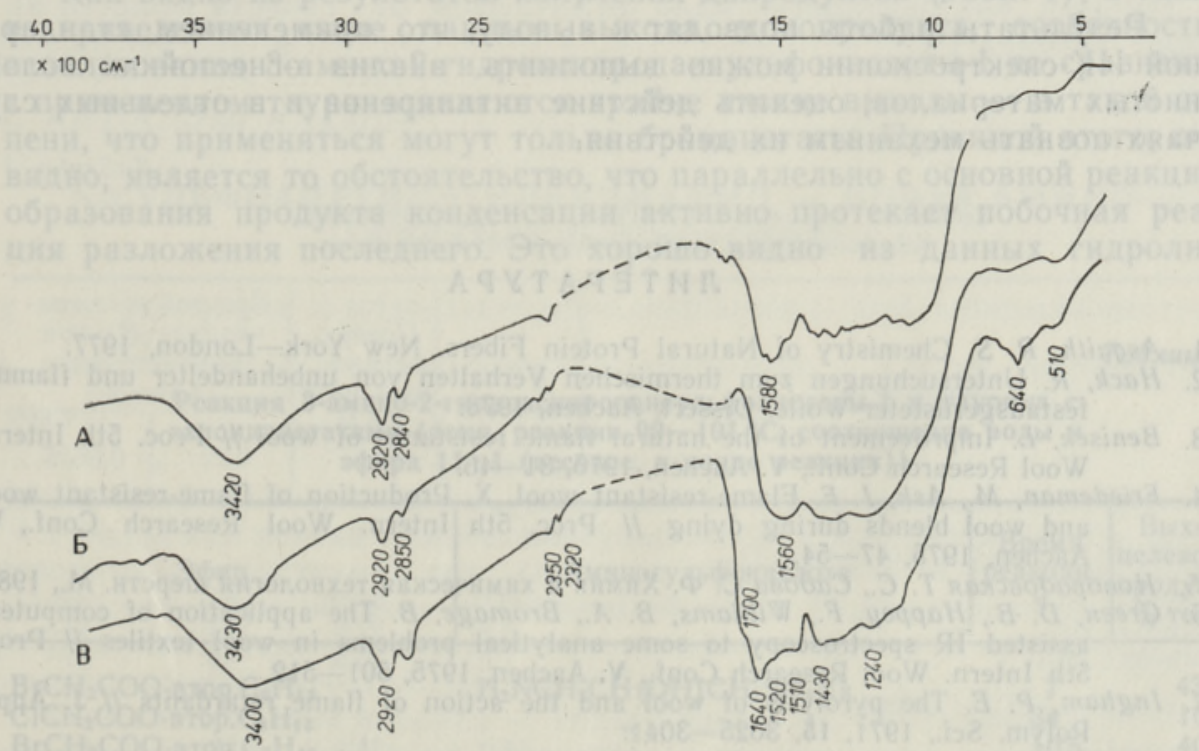

Рис. 5. ИК-спектры пиролизных остатков натуральной шерсти (А), проб № 2 (Б) и № 4 (В). Температура пиролиза $500^{\circ} \mathrm{C}$. 
На спектрах пиролизных остатков проб (рис. 4) видно, что если для необработанной шерсти интенсивность амидных полос начинает уменьшаться (расщепление пептидной цепи с образованием имидной структуры уже при $300^{\circ} \mathrm{C}$ ), то модифицированные варианты матернала более стабильны - пробы № 2 и № 4 сохранили при этой температуре пиролиза свои амидные группы. Для пиролизных остатков модифицированных проб отмечается, как и для натуральной шерсти, увеличение полосы $1660 \mathrm{~cm}^{-1}$, характеризующей полосу имидной структуры $\mathrm{C}=\mathrm{N}$, образовавшуюся в результате разложения полипептидной цепи по механизму, выдвинутому П. Е. Ингхам [7]:

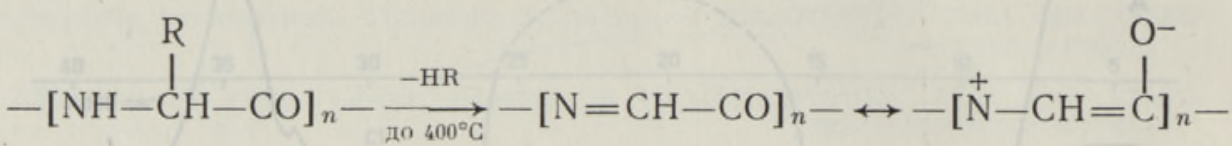

По спектрам можно проследить и за образованием карбонильной полосы при $1710 \mathrm{~cm}^{-1}$, а также за образованием двойной связи $\mathrm{C}=\mathrm{C}$ вследствие пиролиза, полоса которой совпадает с полосой при $1660 \mathrm{~cm}^{-1}$.

Полосы водородных связей для пиролизных остатков шерстей еще сохраняются при температуре пиролиза $300^{\circ} \mathrm{C}$, как и полосы валентных колебаний $\mathrm{CH}_{2}$ - и $\mathrm{CH}_{3}$-групп, хотя известно, что выделение воды начинается для модифицированной шерсти уже при более низкой температуре и идет с бо́льшим выходом, чем для необработанного материала ["].

Анализ остатков высокотемпературного пиролиза показывает, что шерстяные волокна, обработанные одним антипиреном и смесью двух агентов, существенно различаются (рис. 5). Остаток пиролиза пробы № 2 сходен с остатком необработанной шерсти (рис. 5, А и Б), а остаток после обработки смесью агентов доказывает более высокую термостойкость материала: в его спектре полосу остатков амидных групп $\left(1640\right.$ и $\left.1520 \mathrm{~cm}^{-1}\right)$ дополняют полосы $\mathrm{C}=\mathrm{C}$ - и $\mathrm{C}=\mathrm{N}$-связей $\left(1660 \mathrm{~cm}^{-1}\right)$, полоса карбонила $1700 \mathrm{~cm}^{-1}$ и полоса, образовавшаяся в процессе деструкции ароматической структуры при $1510 \mathrm{~cm}^{-1}$. Интенсивность полос валентных колебаний $\mathrm{OH}-, \mathrm{CH}_{2}$ - и $\mathrm{CH}_{3}$-групп одинакова для всех ппоб. В спектрах всех остатков пиролиза $\left(500^{\circ} \mathrm{C}\right)$ имеются слабые $\mathrm{C} \equiv \mathrm{N}$-полосы при 2320 и $2350 \mathrm{~cm}^{-1}$ (рис. 5, B).

Результаты работы подводят к выводу, что применением стандартной ИК-спектроскопии можно выполнить анализ огнестойких волокнистых материалов, оценить действие антипиренов и в отдельных случаях познать механизм их действия.

\section{ЛИТЕРА Т У Р}

1. Asquith, R. S. Chemistry of Natural Protein Fibers. New York-London, 1977.

2. Hack, $R$. Untersuchungen zum thermischen Verhalten von unbehandelter und flammfestausgerüsteter Wolle. Dissert. Aachen, 1978.

3. Benisek, L. Improvement of the natural flame resistance of wool // Proc. 5th Intern. Wool Research Conf., V. Aachen, 1975, 31-46.

4. Friedeman, M., Ash, J. F. Flame-resistant wool. X. Production of flame-resistant wool and wool blends during dying // Proc. 5th Intern. Wool Research Conf., V. Aachen, $1975,47-54$.

5. Новорадовская Т. С., Садова С. Ф. Химия и химическая технология шерсти. М., 1986.

6. Green, D. B., Happey, F., Williams, B. A., Bromage, B. The application of computerassisted IR spectroscopy to some analytical problems in wool textiles // Proc. 5th Intern. Wool Research Conf., V. Aachen, 1975, 501-512.

7. Ingham, P.E. The pyrolysis of wool and the action of flame retardants // J. Appl. Polym. Sci., 1971, 15, 3025-3041.

Ннститут: химии

Академии наук Эстонской ССР
Поступила в редакцию 23/VI 1988 